\title{
Pengelolaan Wisata Tirta pada PT. Benoa Marine Recreation (BMR) Keluharan Tanjung Benoa, Kecamatan Kuta Selatan, Kabupaten Badung
}

Elvina Marleen Souhuwat a, 1, Made Sukana a, 2

1elvinamarleen@gmail.com,2made_sukana@unud.ac.id

a Program Studi S1 Destinasi Pariwisata, Fakultas Pariwisata,Universitas Udayana, Jl. Dr. R. Goris, Denpasar, Bali 80232 Indonesia

\section{Abstract}

The key of success in a company is on how the manager manages the company to survive, to compete, and dominate the market share. Therefore, management is a very important thing of a company, including a company which is running in the marine tourism sector. Benoa Marine Recreation is the first company which started water sport business in Bali and it is very interesting to determine its management. This research aims to determine the marine tourism management of PT Benoa Marine Recreation (BMR) in Tanjung Benoa village, Kuta Selatan subdistrict, Badung regency.

The method used in this research is qualitative method and the data sources is primary data and secondary data. The data collecting method used in this research are observation, interview, and documentation and assisted with data analysis techniques.

The result of this research explains that the management of Benoa Marine Recreation is very well by using kinship system. The functions of management are also running well, such as the planning has running properly, organizing also has running well. Every employes are involved, employees are doing their duty and obligation properly. The actuating has done by the general manager. The general manager also directs and motivates all employees. The coordination between boss and employees has interlaced very well. The controlling of water sport activities which is done by the operational manager also running well.

\section{Keywords: Management, Marine Tourism, Water Sport}

\section{Pendahuluan}

Bali memiliki daya tarik wisata yang beraneka ragam, baik daya tarik wisata alam, budaya, maupun buatan. Salah satu daya tarik wisata buatan yang terpadu dengan alam yaitu water sport. Water sport atau olahraga air merupakan salah satu wisata tirta. Bali saat ini setidaknya memiliki 16 kawasan wisata tirta, salah satu di antaranya berlokasi di Tanjung Benoa. Ditetapkannya Tanjung Benoa sebagai resort wisata tirta sebagaimana tercantum dalam SK Gubernur No. 359/1993. Kawasan Tanjung Benoa sendiri terdapat 42 perusahaan yang bergerak di bidang water sports.

Bisnis perusahaan water sport yang dinilai sangat menguntungkan menyebabkan munculnya persaingan antara perusahaan water sport. Keberhasilan suatu perusahaan dalam berbisnis bisa dicapai melalui pengelolaan yang baik. Pengelolaan yang baik dapat terwujud apabila komponen-komponen di dalamnya berfungsi secara maksimal. Suatu perusahaan yang baik terdapat fungsi-fungsi manajerial yaitu perencanaan, pengorganisasian, pengarahan, dan pengawasan. Masing-masing fungsi saling berkaitan dan merupakan satu kesatuan yang tidak terpisahkan.

Benoa Marine Recreation merupakan perusahaan water sport pertama yang dirintis di Bali. Perusahaan ini sudah berjalan selama 31 tahun dan masih tetap 'eksis' hingga saat ini. Tidak hanya 'eksis' BMR telah menjadi perusahaan water sport terlengkap serta terbesar yang berada di kawasan Tanjung Benoa. Keberhasilan perusahaan ini tidak lepas dari manajemen pengelolaan yang diterapkan. BMR menggunakan sistem kekeluargaan dalam mengelola perusahaannya. Penggunaan sistem yang dinilai sederhana ternyata membuat perusahaan ini mampu bertahan serta bersaing dengan perusahaan water sport lainnya.

Adapun rumusan masalah dalam penelitian ini yaitu bagaimana pengelolaan wisata tirta pada PT Benoa Marine Recreation (BMR) Kelurahan Tanjung Benoa, Kecamatan Kuta Selatan, Kabupaten Badung? Tujuan penelitian ini yaitu untuk mengetahui pengelolaan wisata tirta pada Benoa Marine Recreation (BMR) Kelurahan Tanjung Benoa, Kecamatan Kuta Selatan, Kabupaten Badung. 


\section{TINIAUAN PUSTAKA}

Dalam penelitian ini menggunakan konsep wisata tirta, konsep usaha pariwisata, konsep pengelolaan dan teori manajemen. Undang-Undang No. 10 Tahun 2009 Bab VI Pasal 14 tentang Kepariwisataan menjelaskan bahwa usaha wisata tirta merupakan usaha yang menyelenggarakan wisata dan olahraga air, termasuk penyediaan sarana dan prasarana serta jasa lainnya yang dikelola secara komersial di perairan laut, pantai, sungai, danau dan waduk.

Peraturan Menteri Kebudayaan dan Pariwisata No. PM.90/HK.501/MKP/2010 Bab I Pasal 1 tentang Tata Cara Pendaftaran Usaha Daya Tarik Wisata dijelaskan bahwa usaha daya tarik wisata yang selanjutnya disebut dengan usaha pariwisata adalah usaha pengelolaan daya tarik wisata alam, daya tarik wisata budaya, dan/atau daya tarik wisata buatan/binaan manusia.

\section{Menurut Siswanto} pengelolaan merupakan suatu aktivitas yang sistematis yang saling bersusulan agar tercapai tujuan.

Teori manajemen yaitu suatu proses atau kerangka kerja, yang melibatkan bimbingan atau pengarahan suatu kelompok orang-orang kearah tujuan-tujuan organisasional atau maksud-maksud yang nyata (Terry, 2014: 1). Adapun fungsi-fungsi manajemen yaitu planning, organizing, actuating dan controlling.

\section{METODE}

Penelitian ini dilakukan di kawasan Tanjung Benoa yang terfokus pada PT. Rekreasi Bahari Benoa atau yang lebih dikenal dengan BMR (Benoa Marine Recreation) Dive and Water Sports yang terletak di Jalan Pratama No. 99X, Kelurahan Tanjung Benoa, Kecamatan Kuta Selatan, Kabupaten Badung, Bali, Indonesia.

Data yang digunakan dalam penelitian ini yaitu data kualitatif. data kualitatif merupakan bentuk data naratif, deskriptif dalam kata-kata mereka yang diteliti, dokumen pribadi, laporan wawancara, catatan lapangan, artefak, dokumen resmi dan video tapes, dan dokumen resmi lainnya (J. Moleong, 2012:35).

Sumber data yang digunakan yaitu data primer dan data sekunder. Data primer diperoleh dari hasil hasil observasi dan wawancara mendalam yang diperoleh dari informan yang dianggap berpotensi dalam memberikan informasi yang relevan dan sebenarnya di lapangan. Sedangkan data sekunder diperoleh dari dokumen serta data pendukung lainnya yaitu paket water sport, sejarah perusahaan, struktur organisasi, job description, peraturan kerja, hak dan kewajiban karyawan, dan data karyawan.

Pengumpulan data dilakukan dengan observasi non partisipan, wawancara mendalam, dan dokumentasi. Penelitian ini menggunakan informan pangkal yaitu general manager BMR dan informan kunci yaitu manajer operasional BMR.

Teknik analisis data menggunakan analisis data kualitatif yaitu data reduction, data display, dan conclusion drawing/verification.

\section{HASIL DAN PEMBAHASAN}

\subsection{Gambaran Umum}

Kawasan wisata Tanjung Benoa sangat cocok untuk aktivitas olahraga air karena memiliki pasir putih dan kondisi air laut yang tenang. Terdapat sejumlah perusahaan yang bergerak di bidang water sport salah satunya PT. Rekreasi Bahari Benoa atau yang lebih dikenal dengan BMR (Benoa Marine Recreation) Dive and Water Sports. Perusahaan ini merupakan perusahaan pertama yang merintis usaha water sport yang didirikan pada tanggal 20 Oktober 1985 oleh Alm. I Wayan Suweja yang selanjutnya dikelola oleh keempat anaknya. Selain bergerak di bidang perusahaan water sport, adapun perusahaan cabang milik perusahaan PT. Rekreasi Bahari Benoa yaitu Baliwis Spa, The Whacko Beach Club dan Northcoast Dive \& Water Sports, perusahanperusahan tersebut sudah berjalan dengan lancar dan sukses.

BMR merupakan perusahaan water sport yang paling lengkap di Tanjung Benoa. Terdapat 37 aktivitas yang dapat dilakukan di BMR yaitu parasailing, parasailing adventure, banana boat, jet ski, donut boat, fly fish, butterfly shark, buzz bomb, big gammer, evo pro 2, snipper, outsider 3, connely, big beast, kamakazi, GX 4, R3 inflatable, SR 2, knee board, speed boat, water ski, water ski seat, wake boarding, fly board, hover board, ocean bumper, snorkeling, glass bottom boat, turtle island, aqua lounge, mangrove jungle tour, fishing (coral fishing, trolling fishing, dan sunset fishing), dolphin watching tour, bali ocean walker, diving, power 
dive, dan bali ocean club (fish feeding for zebra fish dan intract and swim with nemo). BMR menawarkan berbagai aktivitas dan wahana air yang beraneka ragam. BMR selalu berinovasi serta mengembangkan aktivitas-aktivitas baru yang berhubungan dengan water sports sehingga wisatawan tidak bosan dengan water sport yang monoton. BMR selalu memberikan produk-produk baru dan menawarkan paketpaket water sport dengan promo yang menarik.

\subsection{Pengelolaan Wisata Tirta pada Benoa Marine Recreation}

Benoa Marine Recreation Dive and Water Sports merupakan perusahaan keluarga sehingga dikelola dan dijalankan oleh anggota keluarga serta keluarga terdekat. BMR secara turun-temurun dikelola oleh anak-anak dari Alm. I Wayan Suweja. Karena merupakan perusahaan keluarga BMR memperkerjakan orang lain untuk menempati posisi bawah, sementara pada posisi tinggi (top manager) dipegang oleh keluarga pemilik perusahaan yang saat ini dikelola oleh I Made Wisaka dan I Nyoman Sarwana. Perusahaan yang menggunakan sistem kekeluargaan, kesempatan kerja tergantung pada keturunan atau kedekatan keluarga, keluarga lebih diutamakan serta masyarakat lokal Tanjung Benoa sangat diutamakan dalam perekruitment karyawan di BMR. Selain itu karena merupakan perusahaan keluarga, BMR sendiri tidak memiliki visi dan misi perusahaan secara jelas. Tidak adanya visi misi tidak membuat perusahaan ini kehilangan arah dan tujuan. BMR memiliki tujuan serta target-target yang akan dicapai dan walaupun dengan sistem kekeluargaan, BMR dapat membuktikan bahwa perusahaan ini bisa mencapai kesuksesan serta keberhasilan sampai saat ini walaupun dengan sistem yang sederhana.

\subsubsection{Perencanaan (Planning)}

Perencanaan adalah proses memutuskan tujuan-tujuan apa yang akan dikejar selama suatu jangka waktu yang akan datang dan apa yang dilakukan agar tujuantujuan itu dapat tercapai (Terry, 2014: 43). Benoa Marine Recreation Dive and Water Sports memiliki perencanaan serta tujuan yang akan dicapai dalam kurun waktu tertentu yaitu memiliki target wisatawan setiap harinya yaitu diharapkan mencapai 500 hingga 1.000 orang yang berkunjung. Untuk mencapai target tersebut, marketing BMR harus mencari banyak relasi terutama travel agent sehingga melakukan kerja sama dengan pihak travel agent sehingga dapat mendatangkan wisatawan lebih banyak lagi agar target dapat tercapai. Sampai saat ini sudah ada 50 travel agent di Bali yang menjadi relasi BMR. Selain itu usaha yang dilakukan dalam mempromosikan BMR agar lebih dikenal dan diminati wisatawan yaitu promosi di media sosial, agen perjalanan online, rent car online, selain media sosial adapun event rutin yang bersifat tahunan bernama Deep and Extreme yang dilaksanakan di Jakarta Convention Centre (JCC) di Jakarta. Selain Jakarta juga mempromosikan ke Surabaya dan kota lainnya dalam bentuk roadshow Jawa, serta untuk promosi ke luar negeri biasanya BMR ikut serta dalam event ADEX (Asia Dive Expo) di Singapore dan Malaysia.

Adapun tujuan lainnya yaitu penjualan produk harus dilakukan semaksimal mungkin dan wisatawan yang datang dapat kembali lagi ke BMR sehingga wisatawan yang datang merupakan repeater guest. Untuk mencapai tujuan tersebut, peran staff handle sangat penting karena mereka yang berhadapan langsung dengan tamu sehingga mereka harus meyakinkan wisatawan agar melakukan aktivitas water sport di BMR. Selain itu staff handle harus memberikan pelayanan prima kepada wisatawan sehingga wisatawan yang datang akan kembali lagi dan menjadi pelanggan setia di BMR.

Adapun perencanaan-perencanaan program dalam jangka pendek dan jangka panjang. Untuk perencanaan jangka pendek yaitu BMR mengembangkan water sports di Nusa Lembongan dan Nusa Penida maupun keluar Bali yaitu mengembangkan water sport di Klaten, Jawa Tengah; Pulau Merah, Banyuwangi, Jawa Timur; Lamongan, Jawa Timur; dan Karimunjawa, Jepara, Jawa Tengah. Dan untuk perencanaan jangka panjang sendiri BMR ingin bergerak di bidang akomodasi yaitu BMR berencana untuk mendirikan hotel di Bali.

\subsubsection{Pengorganisasian (Organizing)}

Organizing atau mengorganisir adalah proses pengelompokan kegiatan-kegiatan untuk mencapai tujuan-tujuan dan penugasan setiap kelompok kepada seorang manajer, yang mempunyai kekuasaan, yang perlu untuk 
mengawasi anggota-anggota kelompok (Terry, 2014: 82). Pengorganisasian organisasi di BMR sudah berjalan dengan baik sesuai dengan fungsi, tugas, dan pekerjaannya masing-masing. Dalam melakukan pengorganisasian seluruh karyawan BMR bekerja sama untuk mencapai tujuan bersama. GM melakukan pendekatan secara kekeluargaan pada setiap karyawan dan tidak segan untuk ikut serta terjun di lapangan untuk melihat cara kerja karyawan sehingga rasa solidaritas manajer dan semua anggota karyawan BMR tetap terjaga dengan baik sampai saat ini. Karena menggunakan sistem kekeluargaan peraturan kerja terkadang suka dilanggar terutama untuk jam kerja baik ketika karyawan masuk dan pulang kerja masih tidak sesuai dengan peraturan kerja. Terdapat beberapa karyawan yang terlambat masuk dan pulang terlebih dahulu sebelum jam kerja selesai. I Nyoman Sarwana selaku general manager BMR sudah mengetahui hal tersebut namun tetap tidak ditegur karena merupakan hal yang sudah biasa. Kembali lagi kepada sistem kekeluargaan yang ada di BMR membuat karyawannya bersikap santai kepada perusahaan.

Dalam merekrut karyawan, BMR hanya menggunakan sistem kekeluargaan maka jika dibutuhkan karyawan hanya diberitahukan kepada karyawannya untuk menawarkan kepada kerabat terdekat dan diperuntukkan untuk masyarakat lokal Benoa namun adapun juga menggunakan iklan lowongan kerja dan biasanya ini diluar masyarakat lokal Benoa untuk bagian accounting, marketing dan staff handle. BMR tidak memiliki kontrak kerja secara tertulis atau tidak adanya ikatan kerja dengan BMR. Walaupun terbilang sederhana, namun dengan pola seperti itu tidak ada karyawan yang mengundurkan diri, karyawan bersikap segan terhadap atasan serta sangat menghormati atasan. Untuk gaji karyawan dinilai masih belum sesuai dengan UMR (Upah Minimum Regional) karena ada gaji karyawan yang dibawah UMR dan adapun gaji karyawan yang jabatannya sudah tinggi melebihi standar UMR atau dapat dikatakan mendapat gaji yang besar. BMR memiliki 195 karyawan dan menurut GM BMR sudah mencukupi kebutuhan dalam manajemen BMR dan aktivitas water sport sendiri. Karyawan di BMR di dominasi masyarakat lokal Tanjung Benoa serta masyarakat pendatang yang didominasi oleh orang yang berasal dari Banyuwangi dan Timor. Adapun masyarakat Bali yang bukan masyarakat lokal Tanjung Benoa yang bekerja sebagai karyawan BMR, biasanya didominasi oleh masyarakat dari Pulau Serangan.

\subsubsection{Penggerakan (Actuating)}

Actuating merupakan implementasi dari perencanaan dan pengorganisasian, dimana seluruh komponen yang berada dalam satu sistem dan satu organisasi tersebut bekerja secara bersama-sama sesuai dengan bidang masing-masing untuk dapat mewujudkan tujuan. Mekanisme kerja pada perusahaan BMR yaitu wisatawan yang datang disambut dengan hospitality yang baik serta dihandle oleh staff handle lalu jika wisatawan sudah memilih aktivitas water sports maka langkah selanjutnya adalah melakukan pembayaran ke kasir. Setelah itu akan diberikan tiket misalkan tiket aktivitas parasailing sebagai tanda bukti pembayaran, biasanya tiket tersebut diberikan kepada ketua divisi misalkan divisi parasailing atau divisi lainnya.

Untuk aktivitas water sports sendiri tidak ada briefing setiap harinya, ada kalanya dilakukan briefing jika wisatawan yang datang dalam bentuk group dan dalam jumlah banyak. Tujuan dilakukannya briefing agar tidak terjadi permasalahan atau complain. Jika terjadi kecelakaan pada aktivitas water sports maka ada cover asuransi dari Jasa Raharja. Jika menyebabkan cacat fisik maka akan ditanggung dana sebesar Rp 50.000.000,- jika hingga menyebabkan kematian maka akan ditanggung dana sebesar Rp 100.000.000,-. Namun sampai saat ini belum ada kecelakaan yang fatal hanya sekedar lecet karena terbentur karang.

Dalam pelaksanaan aktivitas water sports, pengarahan karyawan dilakukan oleh general manager sendiri kepada seluruh karyawannya yang dilakukan dengan cara mengawasi kinerja karyawannya apakah sudah mengerjakan perkerjaannya di bidangnya masing-masing untuk mencapai tujuan perusahaan. Target wisatawan yang ditetapkan BMR belum mencapai target, pada kenyataannya hanya mencapai 400 wisatawan pada saat low season, maka solusi dari GM sendiri yaitu bagian marketing melakukan pendekatan ke travel agent, menawarkan promo serta paket water sport yang menarik serta menawarkan produk baru BMR. Walaupun targetnya saat ini belum tercapai, 
namun jika high season biasanya wisatawan yang datang membludak dan melebihi target yang ditetapkan. Hal itu membuktikan bahwa pengarahan organisasi yang dilakukan oleh GM telah tercapai dengan baik. Koordinasi GM terhadap karyawan-karyawannya sangat baik dengan komunikasi yang intensif, tidak ada perbedaan antara atasan dan bawahan, semua dianggap sama rata.

Peranan GM yang selalu berusaha menanamkan nilai gotong royong kepada para karyawan, sehingga rasa solidaritas yang tinggi antara para karyawan terbentuk secara alamiah. Karyawan saling menghargai satu sama lain dan menimbulkan rasa kekeluargaan dalam bekerja. Sehingga tidak pernah terjadi konflik antar pegawai maupun dengan GM. GM juga selalu menghimbau bahwa pelayanan yang utama bagi wisatawan dengan menerapkan $3 \mathrm{~S}$ (senyum, sapa, dan salam) serta tidak mencampurkan urusan pribadi dengan pekerjaan. Karyawan juga dituntut bertanggung jawab serta jujur demi mewujudkan tujuan bersama. GM akan memanggil karyawan yang bersangkutan dan memberikan teguran secara langsung apabila ada karyawan yang tidak disiplin atau malas-malasan saat jam kerja serta menasehati karyawan tersebut dan kemudian mencari jalan keluar yang terbaik. Hal tersebut membuat para karyawan merasa nyaman dalam keterbukaan pada GM, sehingga tercipta suasana yang kondusif untuk melanjutkan pekerjaan.

\subsubsection{Pengawasan (Controling)}

Pengawasan adalah dalam bentuk pemeriksaan untuk memastikan, bahwa apa yang sudah dikerjakan adalah juga dimaksudkan untuk membuat sang manajer waspada terhadap suatu persoalan potensial sebelum persoalan itu menjadi serius. Pengawasan adalah suatu proses dasar, serupa saja dimanapun ia terdapat dan apapun yang diawasi. (Terry, 2014:232). Dalam pengelolaan pada BMR yang melalukan pengawasan pada manajemen BMR yaitu general manajer dan pengawasan pada aktivitas water sport sendiri adalah manajer operasional. Pembagian departemen pada manajemen memudahkan proses pengawasan di BMR. Karena setiap aktivitas water sports memiliki head staffnya sendiri. Sehingga jika ada masalah ataupun hal lainnya, head staff langsung mengatakan kepada manajer water sports setelah itu baru mengatakan kepada manajer operasional. Manajer operasional bertugas menyelesaikan masalah atau menghandle complain sampai kecelakaan jika terjadi. Jika masalah tersebut tidak dapat diselesaikan oleh manajer operasional, maka manajer operasional baru melaporkan kepada general manager. Untuk pengawasan perlengkapan dan peralatan water sports dilakukan setiap hari pada sore hari setelah kegiatan aktivitas water sport selesai sehingga keesokan harinya perlengkapan dan peralatan water sports bisa langsung digunakan. Yang melakukan pengecekan alat tersebut adalah setiap head staff water sports.

Kualitas karyawan yang ada di BMR sudah sangat baik. Karyawan di BMR sudah bekerja sesuai dengan standar operasional prosedur (SOP), sudah sesuai dengan pembagian kerja dan sesuai dengan bidang dan fungsinya masing-masing serta sudah mentaati peraturan kerja yang ada. Namun dengan sistem kekeluargaan yang dipergunakan menyebabkan terkadang peraturan kerja tersebut dilanggar. Untuk menilai kinerja karyawannya, GM selalu mereview karyawannya dilihat dari kedisiplinan, niat kerja atau kemauan kerja, kemampuan kerja, tanggung jawab serta hasil kerja karyawannya.

Adapun pengawasan mengenai manajemen di BMR sendiri yaitu evaluasi mengenai pemasukan dan pengeluaran BMR yang biasanya dilakukan seminggu sekali. Ada juga dalam bentuk meeting umum yang diikuti oleh seluruh manajemen dan seluruh karyawan BMR yang dilaksanakan sekali dalam satu bulan. Meeting ini membahas mengenai masalah-masalah yang dihadapi, bagaimana menghadapi masalah tersebut, bagaimana meningkatkan kunjungan wisatawan, dan sebagainya. Pada umumnya meeting ini merupakan evaluasi bulanan yang dilakukan oleh perusahaan BMR. Selain meeting umum ada meeting per divisi yang biasanya dilakukan satu kali atau lebih dalam sebulan sehingga bersifat fleksibel tergantung adanya permasalahan. Adapun evaluasi tahunan, biasanya mengenai pendapatan, keuntungan dari aktivitas water sport sendiri, gaji karyawan, hutang perusahaan, dan lain-lain. Dalam evaluasi ini juga direncanakan programprogram atau tujuan yang akan dicapai untuk tahun berikutnya. 


\section{SIMPULAN DAN SARAN}

\subsection{Simpulan}

Berdasarkan hasil penelitian ini, maka dapat disimpulkan bahwa pengelolaan di Benoa Marine Recreation (BMR) sudah baik dengan menggunakan sistem kekeluargaan. Adapun kesimpulan berdasarkan fungsi manajemen yaitu sebagai berikut:

1) Perencanaan yang dilakukan oleh Benoa Marine Recreation sudah berjalan dengan baik.

2) Pengorganisasian sudah berjalan dengan baik. Seluruh karyawan dilibatkan, karyawan sudah sesuai dengan tugas dan kewajibannya masingmasing.

3) Penggerakan sudah dilakukan oleh general manager sendiri yang menagarahkan serta memotivasi karyawannya. Koordinasi antara atasan dan bawahan sudah terjalin dengan sangat baik.

4) Pengawasan manajemen yang dilakukan dengan general manager sudah baik. Sedangkan pengawasan aktivitas water sport yang dilakukan manajer operasional juga sudah berjalan dengan baik.

\subsection{Saran}

1) Perlu adanya visi dan misi perusahaan secara jelas mengingat pentingnya visi dan misi sehingga perusahaan dapat berjalan dengan baik sesuai dengan arah dan tujuan perusahaan.

2) General manager harus bersikap lebih tegas terhadap karyawannya terutama terkait dengan peraturan kerja yang sering dilanggar karyawannya. Walaupun BMR menggunakan sistem kekeluargaan, hal tersebut tidak dapat dijadikan alasan untuk karyawan yang sering telat masuk kerja dan pulang sebelum jam yang ditentukan.

3) Seharusnya dilakukan briefing dan debriefing setiap harinya sehingga pelayanan yang dihasilkan kepada wisatawan bisa lebih baik lagi atau terciptanya pelayanan prima.

4) Gaji karyawan seharusnya sesuai dengan upah minimum regional (UMR) Kabupaten Badung.

\section{DAFTAR PUSTAKA}

Anonim. 2009. Undang Undang Republik Indonesia No. 10 Tahun 2009 Tentang Kepariwisataan

Anonim. 2010. Peraturan Menteri Kebudayaan dan Pariwisata No. PM.90/HK.501/MKP/2010 Tentang Tata Cara Pendaftaran Usaha Daya Tarik Wisata

Moleong, Lexy J. 2012. Metode Penelitian Kualitatif. Bandung: PT Remaja Rosdakarya.
Siswanto, B. 2005. Pengantar Manajemen. Jakarta: Bumi Aksara

Sugiyono. 2008. Metode Penelitian Pendidikan. Bandung: Alfabeta.

Terry, George R dan Leslie W. Rue. 2014. Dasar-dasar Manajemen. Jakarta: Bumi Aksara 